\title{
Hypoxia and cancer
}

\author{
M. Christiane Brahimi-Horn • Johanna Chiche • \\ Jacques Pouysségur
}

Received: 28 September 2007 / Revised: 22 October 2007 / Accepted: 23 October 2007 / Published online: 20 November 2007

(C) Springer-Verlag 2007

\begin{abstract}
A major feature of solid tumours is hypoxia, decreased availability of oxygen, which increases patient treatment resistance and favours tumour progression. How hypoxic conditions are generated in tumour tissues and how cells respond to hypoxia are essential questions in understanding tumour progression and metastasis. Massive tumour-cell proliferation distances cells from the vasculature, leading to a deficiency in the local environment of blood carrying oxygen and nutrients. Such hypoxic conditions induce a molecular response, in both normal and neoplastic cells, that drives the activation of a key transcription factor; the hypoxia-inducible factor. This transcription factor regulates a large panel of genes that are exploited by tumour cells for survival, resistance to treatment and escape from a nutrient-deprived environment. Although now recognized as a major contributor to cancer progression and to treatment failure, the precise role of hypoxia signalling in cancer and in prognosis still needs to be further defined. It is hoped that a better understanding of the mechanisms implicated will lead to alternative and more efficient therapeutic approaches.
\end{abstract}

Keywords Angiogenesis · Autophagy · Bcl-2/adenovirus EIB $19 \mathrm{kDa}$-interacting protein 3 - Cancer .

Carbonic anhydrase $\cdot$ Hypoxia $\cdot$ Hypoxia-inducible factor . Oxygen-sensor $\cdot$ Tumour metabolism $\cdot \mathrm{pH}$ regulation

M. C. Brahimi-Horn $(\bowtie) \cdot J$. Chiche $\cdot$ J. Pouysségur

Institute of Signaling, Developmental Biology and Cancer Research, University of Nice,

CNRS UMR 6543, Centre A. Lacassagne,

33 Avenue Valombrose,

06189 Nice, France

e-mail: brahimi@unice.fr

\section{Introduction}

Cancer is presently a major cause of mortality in developed countries and will become even more so in low-income countries as the global population increases and ages and as improvements in detection are implemented [1]. Although some cancers occur in the young, most are associated with the elderly, and both events represent the accumulation of genetic and epigenetic cell damage [2]. Cancer includes a diverse collection of diseases, from a cellular origin point of view, rather than a single disease, the causes of which are equally as diverse [3]. Aberrant cell-cycle checkpoint control, overactivation of oncogenes and inhibition of tumour-suppressor genes are considered to be primordial in the initiation of tumourigenesis. However, other factors related to the tumour microenvironment are now being recognized as fundamental in tumour progression, increased resistance and metastasis. Hypoxia is one of these factors, the repercussions of which are shared by all cancer types including haematological cancers [4].

\section{The hypoxic tumour phenotype}

Robust tumour growth requires the presence of a local vascular network that supplies both oxygen and nutrients to tumour cells. However, a highly proliferating mass of tumour cells develops faster than the vasculature, and tumour cells rapidly meet up with an avascular environment deficient in oxygen, i.e. hypoxic. This is a consequence of the diffusion limit of oxygen within tissues, which has been measured to be around $150 \mu \mathrm{m}[5,6]$ (Fig. 1). On histological examination, tumours often show a central core of necrotic cells, which has been suggested to result from a drop in the oxygen availability to conditions of severe hypoxia and glucose 

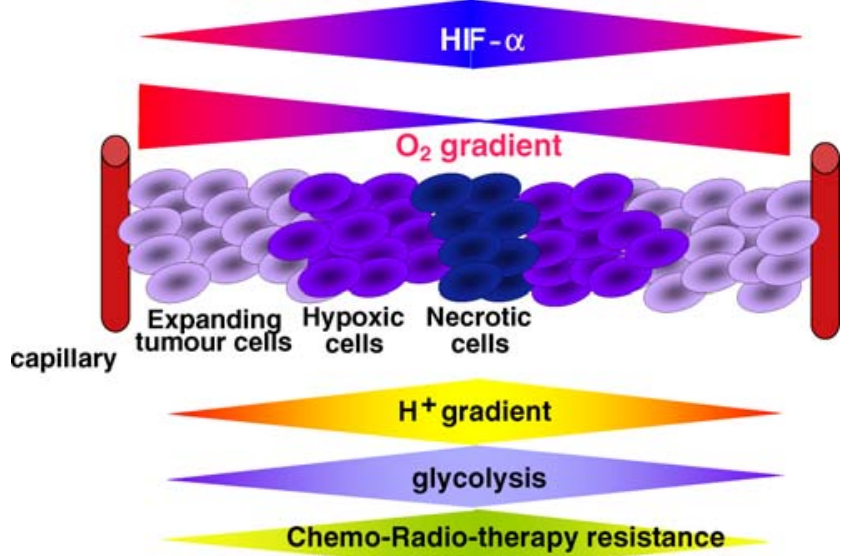

Fig. 1 The characteristics of a hypoxic tumour mass. Blood capillaries carry oxygen to tissues, but since oxygen has a diffusion limit, its concentration decreases as the distance from capillaries increases. Macroscopic examination of solid tumours reveals the presence of expanding tumour cells in proximity to capillaries and a central region of necrotic cells. This gradient of cell viability parallels that of a decreasing gradient of oxygen, which is accompanied by an increase in HIF- $1 \alpha$ levels, a decrease in the extracellular $\mathrm{pH}$ and an increase in the resistance to radio- and chemo-therapy

deprivation resulting in cell death. A number of methods have been developed to measure the oxygen concentration in tissues including chemical markers such as pimonidazole hydrochloride or EF5, oxygen miocroelectrodes or optical partial pressure of oxygen-measuring devices. Such hypoxic zones have been postulated to have a reduced response to radiotherapy due to a decrease in oxygen-free radicals that are required to produce enough DNA damage to give cell death [7]. In addition, cells of these regions are considered to be chemotherapy-resistant due to limited delivery of drugs via the circulation. Hypoxic tumours also show an extracellular $\mathrm{pH}(\mathrm{pHe})$ that is lower than that of corresponding normal tissue [8]. The acidotic nature is the consequence of a modification in the metabolism of tumour cells, in particular that of glucose [9] (Fig. 1).

\section{Hypoxia-inducible factor, the molecular key to hypoxia}

Hypoxia activates an alpha/beta heterodimeric transcription factor termed appropriately the hypoxia-inducible factor (HIF). Activation resides in the inhibition of posttranslational hydroxylation of the alpha subunit that permits stabilization, heterodimerisation and binding to hypoxiaresponse elements (HRE) in target genes. The details of the mechanisms of regulation of the stability and activity of HIF- $\alpha$ have been extensively reviewed by us [10-12] and others [13-16]. Suffice it to say that posttranslational hydroxylation by oxygen-dependent oxygenases, prolyl hydroxylase domain proteins and factor inhibiting HIF
(FIH) destabilize and inactivate, respectively, HIF- $\alpha$. The former, by favouring von Hippel-Lindau (VHL) E3 ubiquitin ligase-mediated proteasomal degradation, and the latter, by inhibiting interaction with co-activators such as $\mathrm{p} 300 / \mathrm{CBP}$.

\section{The HIF-mediated cellular response}

Non-hydroxylated, active HIF- $\alpha / \beta$ targets about $1-2 \%$ of the human genome leading to induction or repression of genes with subsequent up- or down-regulation of expression, respectively, of the corresponding gene products. A broad range of genes that are implicated in events such as angiogenesis, cell survival/death, metabolism, $\mathrm{pH}$ regulation, adhesion, extracellular matrix remodeling, migration and metastasis are targeted $[12,15,17,18]$. The functional consequences of enhanced expression of a small selection of some of these gene products are discussed below (Fig. 2).

\section{Angiogenesis}

HIF-mediated expression of gene products including the vascular endothelial growth factor-A (VEGF-A) and angiopoïetin-2 (Ang-2) allow tumour cells to turn around the hypoxic situation by inducing regrowth of the vascular network, a phenomenon termed angiogenesis [19]. Thereby an oxygenated and nutritional environment is reestablished for maintenance of growth. However, the neo-vessels formed are often distorted and irregular and thus less efficient in oxygen, nutrient transport and drug delivery.

\section{Cell survival or death}

Thus, hypoxia initiates a cascade of events that allows tumour cells to continue to proliferate; however, if too severe, hypoxia can also lead to cell death as shown by the presence in tumours of a central necrotic zone. In fact, it can be envisaged that highly variable levels of hypoxia accompany the dynamics of spatiotemporal development of the tumour mass so that a multitude of tumour cell responses are manifested (Fig. 1). Interplay between FIH and the transcriptional activation domains of HIF-1 $\alpha$, based on the degree of oxygen dependence of FIH for activity, has been proposed to select for different gene profiles that determine cell fate [20]. Gene-profile selectivity may also arise from differential action of the three HIF- $\alpha$ subunits and, within the context, may promote cell proliferation or death $[21,22]$. The genes bnip3, Bcl-2/adenovirus EIB $19 \mathrm{kDa}$-interacting protein 3, and bnip3L (bnip3-like), the products of which are members of the $\mathrm{BH} 3$-only protein family of cell death factors, are highly induced in hypoxia. 


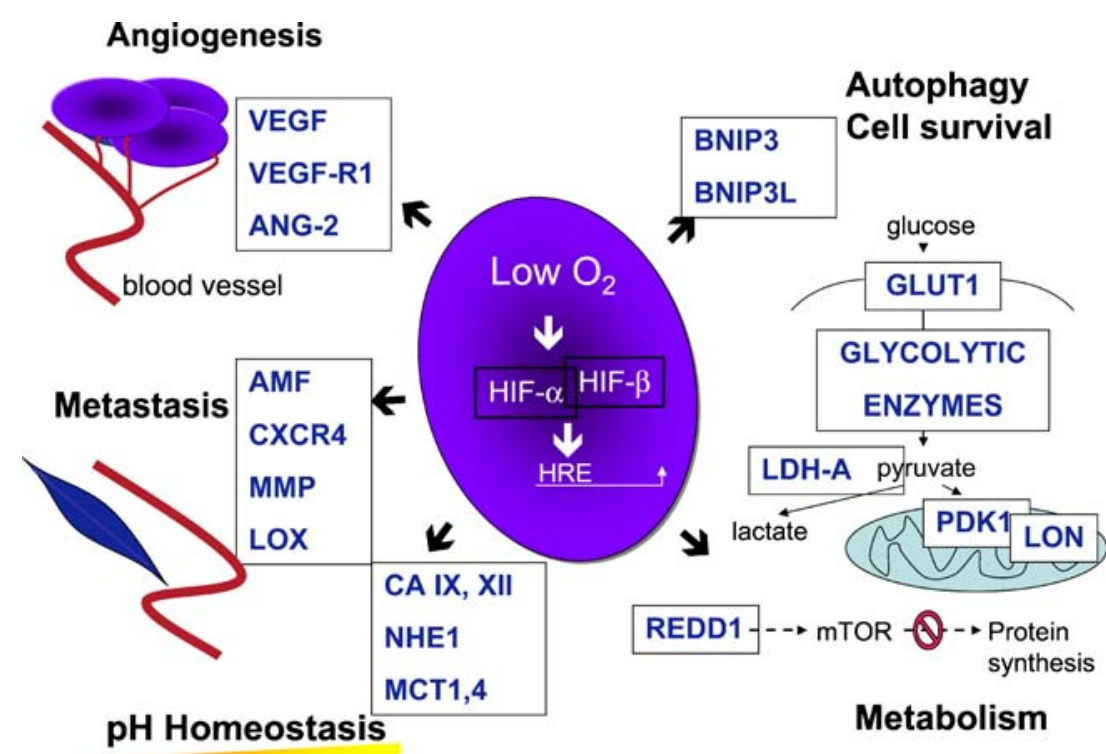

Fig. 2 HIF-induced gene products and their function. The $\alpha / \beta$ heterodimer HIF bound to hypoxia-response elements $(H R E)$ in target genes mediates the expression of a vast array of proteins implicated in functions such as angiogenesis, cell survival/death, metabolism, $\mathrm{pH}$ homeostasis and metastasis. A small selection of proteins (boxed, in blue) is shown and include: $A M F$ autocrine motility factor; $A N G-2$ angiopoïetin-2; $B N I P 3 \mathrm{Bcl}-2 /$ adenovirus EIB $19 \mathrm{kDa}$-interacting protein 3; $B N I P 3 L \mathrm{Bcl}-2 /$ adenovirus EIB $19 \mathrm{kDa}$-interacting protein

Although many studies have pointed at the pro-apoptotic features of these two gene products, these findings are largely controversial. We propose instead that the $\mathrm{BH} 3$ domains of BNIP3 and BNIP3L belong to another class, like the BH3 domain of Beclin1, that do not induce cell death but survival by triggering autophagy [12, 23, 24]. Macroautophagy is a process that allows cells to recycle intracellular organelles such as ribosomes and mitochondria for nutritional and protective purposes [25]. Catabolism of organelle components provides nutrient-depleted cells with a source of lipids, amino acids and sugars, and autophagy of mitochondria may protect cells from harmful reactive oxygen species.

\section{Metabolism}

A substantial number of genes involved in cellular metabolism, in particular those of glucose, are HIFmediated. It has been known for many years that cancer cells divert pyruvate metabolism away from mitochondrial oxidative phosphorylation (OXPHOS) toward cytoplasmic conversion of pyruvate to lactic acid [11]. Although this latter simplified pathway produces less adenosine triphosphate (ATP) per molecule of glucose, cells compensate for a reduced yield in ATP production by increasing both the uptake of glucose and the flux in conversion of glucose to pyruvate, i.e. glycolysis. This is made possible through an
3 like; $C A I X, X I I$ carbonic anhydrase; $C X C R 4$ cytokine (C-X-C motif) receptor 4; GLUT1 glucose transporter 1; $L D H-A$ lactate dehydrogenase-A; $L O N$, a mitochondrial protease; $L O X$ lysyl oxidase; $M C T 1,4$, monocarboxylate transporter; $M M P$ matrix metalloproteinase; $N O X A$ pro-apoptotic member of $\mathrm{Bcl}-2$ protein family; $P D K 1$ pyruvate dehydrogenase kinase 1; REDD1/RTP801; VEGF vascular endothelial growth factor; $V E G F-R 1$, vascular endothelial growth factor receptor

increase in HIF-mediated expression of both glucose transporters and enzymes of the glycolytic pathway, giving tumours a "glycolytic" phenotype. Diversion of pyruvate toward lactate and away from OXPHOS is also promoted through increased HIF-mediated expression of two key enzymes; lactate dehydrogenase A (LDH-A) [26] and pyruvate dehydrogenase kinase 1 (PDK1) [27, 28]. LDH$\mathrm{A}$ is the enzyme responsible for conversion of pyruvate to lactate, and PDK1 is an inhibitor of pyruvate dehydrogenase that feeds pyruvate into the tricarboxylic acid cycle and thus toward OXPHOS. Thereby, HIF not only channels glucose towards glycolysis by repressing mitochondrial respiration but it also optimizes low levels of respiration by regulating the ratio of isoforms of cytochrome c oxidase, components of the electron transport chain [29]. This strategy not only makes respiration more efficient but may also protect cells from oxidative damage under hypoxic conditions. Metabolic regulation via HIF also brings into play products of tumour suppressors and oncogenes such as p53, c-Myc, Ras and Akt [11, 21, 30].

Another pathway related to nutrient availability, which is modified by HIF, is that of mammalian target of rapamycin (mTOR). On the one hand, growth factors and nutrients potentiate the mTOR pathway in conveying signals of growth and survival through increased protein synthesis, and on the other hand, energy depletion and hypoxia suppress mTOR, saving on energy-consuming protein 
synthesis, allowing for cellular adaptation and subsequent survival [12].

\section{Regulation of $\mathrm{pH}$}

One of the consequences of the predilection of cancer cells for cytoplasmic glucose metabolism in producing lactic acid is acidosis, a decrease in the extracellular $\mathrm{pH}$ [31]. This acidosis, generated by the increased production of carbonic and lactic acids, is exacerbated by the limiting vasculature. Despite a low $\mathrm{pHe}$, the intracellular $\mathrm{pH}(\mathrm{pHi})$ of tumour cells is maintained at a relatively normal $\mathrm{pH}$ or even slightly more alkaline $\mathrm{pH}$, which is reported to result from HIF-mediated up-regulation and activation of a number of membrane located transporters, exchanges, pumps and ecto-enzymes that are implicated in $\mathrm{pH}$ homeostasis. Among these are the growth factor activatable and amiloride-sensitive $\mathrm{Na}^{+} / \mathrm{H}^{+}$Exchanger (NHE-1) [32-34] and the $\mathrm{H}^{+}$/lactate cotransporter (monocarboxylate transporter, MCT1 and MCT4) [35]. In addition, one of the most highly HIF-induced proteins, carbonic anhydrase IX (CA IX), an enzyme that catalyzes the reversible conversion of $\mathrm{CO}_{2}$ to carbonic acid (Fig. 3), has been reported to regulate the $\mathrm{pHe}$ [36], and we propose that it may contribute to an increase in the $\mathrm{pHi}$ through $\mathrm{Cl}^{-} / \mathrm{HCO}_{3}^{-}$ exchanger uptake of $\mathrm{HCO}_{3}^{-}$. Coupled interaction between MCT1 [37] and CA II and between different CA isoforms and proteins of the superfamily of bicarbonate transporters, including the anion exchangers [38, 39] or sodium bicarbonate co-transporter (NBCs) proteins [39] has been reported. Such interplay would allow tumour cells to maintain a more alkaline $\mathrm{pH}$ for subsequent cell growth [40].

\section{Metastasis}

Substantial data points toward hypoxic promotion of the invasive potential of tumour cells. HIF activation is associated with loss of E-cadherin, a component of adherens junctions that acts as a suppressor of invasion and metastasis [41]. In this context, it is interesting that TWIST1, a regulator of epithelial-mesenchymal transition [42], is induced in hypoxia [43]. In addition, cells that survive acidosis not only develop a growth advantage but also become more aggressive and invasive [6,44]. This occurs in part through the activation of HIF-up-regulated proteins implicated in matrix remodeling, such as lysyl oxydase (LOX) [12, 45], metalloproteases that disrupt cellcell and cell-matrix (ECM) interactions [46]. HIF also activates other genes known to be involved in metastasis and invasion such as the c-met proto-oncogene, the chemokine receptor CXCR4 and the autocrine motility factor (AMF) [41, 47].

\section{Clinical significance of hypoxia, HIF and HIF downstream gene products in prognosis}

Since hypoxia in tumours and internalization of high levels of glucose into tumours are considered to be indicators of more aggressive tumours, and thus of poor patient prognosis [48], attempts to detect these characteristics in patients' tumours have been developed using positron emission tomography (PET). Hypoxic zones are detected after injection of [fluorine-18] misonidazole (FMISO), while tumours that capture glucose can be detected after injection of [fluorine-18] deoxyglucose (FDG), a non-

\section{Human colon adenocarcinoma}

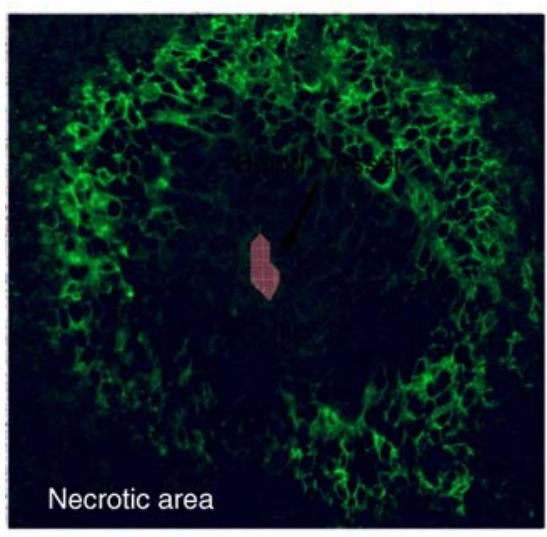

CA IX

Fig. 3 Tumour expression of carbonic anhydrase IX (CA IX) and hypoxia-inducible factor- $1 \alpha$ (HIF-1 $\alpha)$. Immunohistological detection of CA IX and HIF- $1 \alpha$ colocalized in hypoxic regions of a section of a human

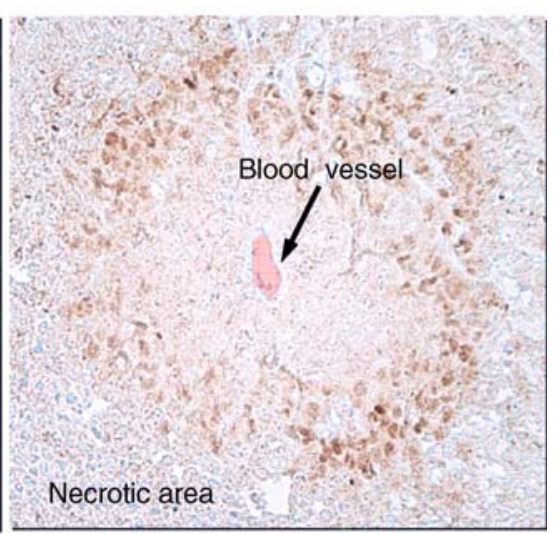

HIF- $1 \alpha$

colon adenocarcinoma (LS174) grown in nude mice (Dayan et al., unpublished data). Note the hypoxic gradient that develops away from the blood vessel and the necrotic area around the most hypoxic ring 
metabolizable analogue of glucose (Fig. 4). However, a direct correlation between high glucose uptake and hypoxic regions was not observed $[49,50]$. This may result from the fact that only highly hypoxic regions, though not necrotic, are detected with FMISO, so areas where the oxygen concentration is nonetheless sufficiently low for stablization of HIF- $\alpha$ may not be identified. Alternatively, cycles of hypoxia and angiogenic reoxygenation that give rise to a high glucose capture phenotype may have preceded analysis. The recognition that hypoxic areas are radiotherapy resistant has led to a number of strategies to increase the oxygen availability or to deliver radiosensitizing agents [7].

Since HIF- $\alpha$ and HIF-induced proteins such as CA IX, CA XII and Glutl are highly expressed in renal cell carcinomas (RCC) and in multiple human cancers, their expression has been investigated as markers of tumour aggressiveness and in determining prognosis [22]. RCC is a prototype cancer for understanding the role of HIF in cancer progression since it carries loss-of-function mutations in the $V H L$ gene, the product of which is responsible for targeting HIF- $\alpha$ for proteasomal degradation [51]. Thus, in these cancers, HIF- $\alpha$ is stable, and downstream gene products are induced. To better appreciate the implication of HIF in tumour progression and prognosis, immunohistochemical studies have been performed in several other cancer types to detect for both HIF- $\alpha$ and HIF-downstream gene products such as BNIP3, CA IX and XII, Glut1 and

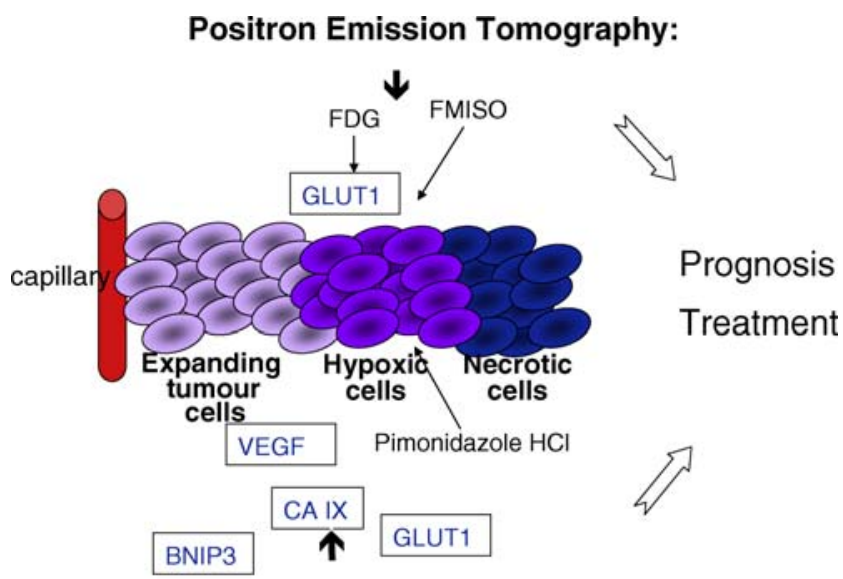

Immunohistochemistry:

Fig. 4 Clinical significance of hypoxia and HIF in prognosis. Imaging by PET allows detection of hypoxic zones and zones of high glucose uptake in tumours after injection to patients of [fluorine-18] misonidazole (FMISO) or [fluorine-18] deoxyglucose (FDG), respectively. Immunohistochemistry of surgical specimens allows detection of hypoxic regions using primonidazole $\mathrm{HCl}$ and detection of HIF-target gene products such as BNIP3 $\mathrm{Bcl}-2$ / adenovirus EIB $19 \mathrm{kDa}$-interacting protein 3; $C A I X$ carbonic anhydrase; GLUT1 glucose transporter 1; VEGF vascular endothelial growth factor. Further studies are required to determine the clinical potential of such imaging technologies in prognosis and treatment of different cancer types
VEGF (Figs. 3 and 4). The inherent problem related to the detection of HIF- $\alpha$ in tissue specimens is the short half-life of HIF- $\alpha$ not only in vivo but also when the specimen comes in contact with atmospheric oxygen during surgical removal. In fact, recent studies have established that this was not the case and make these studies reporting levels of HIF- $\alpha$ relevant [52]. It was shown that HIF- $1 \alpha$ and CA IX expression correlate with poor prognosis in breast cancer [52]. The longer half-life of the other potential marker proteins may make interpretation difficult as detection may reflect only past events. These markers were shown to correlate for both primary breast tumours and lymph node metastases [53], and further studies have demonstrated reduced survival correlated with CA IX expression in breast cancer [54]. In breast cancer, high BNIP3 expression was associated with good survival outcome in invasive carcinoma but with an increased risk of recurrence and shorter disease-free survival in ductal carcinoma in situ [55], while in non-small lung cancer, high expression was an independent factor for overall survival [56]. Further investigation is required to obtain a better appreciation of the value of HIF or HIF-related marker immunohistochemistry for prognosis.

\section{Harnessing phenotype in combating tumour growth}

Novel processes that engage perturbations in the tumour microenvironment may prove efficient as cancer therapies. Inhibition of angiogenesis, although not devoid of harmful side effects, is showing potential in treatment of several different types of cancer when in combination with classical chemotherapy [57]. Both intervention at the level of HIF [58] and HIF downstream genes, in addition to those that regulate angiogenesis, merit investigation (Fig. 5). Alternative strategies that target the particularities of the tumour

\section{Harnessing tumour phenotype in cancer treatment}

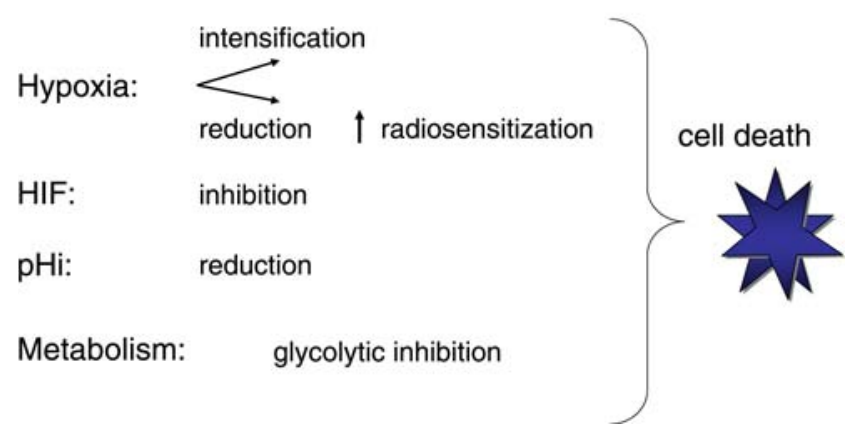

Fig. 5 Potential novel approaches to turning around the hypoxic tumour phenotype. By controlling the hypoxic nature of tumours and the HIF-mediated cellular adaptation or microenvironmental consequences, such as acidosis, novel therapeutic approaches should promote cell death 
phenotype may provide tumour-specific agents that hold the advantage of sparing normal tissue [59-61], which is not the case with classical chemotherapy. Such strategies may prove beneficial alone or in combination with presently employed cytotoxic agents [62].

\section{Conclusions}

The understanding of how hypoxia drives tumour progression is attracting substantial investigation, and an impressive number of reviews have ensued; however, a lot remains to be done to clarify not only the mechanisms involved but also the implication for diagnosis and treatment. Further investigation into the relevance of HIFinduced gene products as markers of prognosis should follow. The development of anti-angiogenic agents with significant potential as a cancer therapy has led the way in demonstrating that the hypoxic response of tumours can be targeted. Additional targets involved in HIF signalling and in its consequences should also prove beneficial in slowing cancer progression and metastasis.

Acknowledgments The laboratory is funded by grants from the Ligue Nationale Contre le Cancer (Equipe labellisée), the Centre A. Lacassagne, the Centre National de la Recherche Scientifique (CNRS), the Ministère de l'Education, de la Recherche et de la Technologie, the Institut National de la Santé et de la Recherche Médicale (Inserm), and the Institut National du Cancer (INCA). We apologize to the many research groups whose work was cited indirectly by reference to review articles.

\section{References}

1. Bray F, Moller B (2006) Predicting the future burden of cancer. Nat Rev Cancer 6:63-74

2. Finkel T, Serrano M, Blasco MA (2007) The common biology of cancer and ageing. Nature 448:767-774

3. Colditz GA, Sellers TA, Trapido E (2006) Epidemiologyidentifying the causes and preventability of cancer? Nat Rev Cancer 6:75-83

4. Moehler TM, Ho AD, Goldschmidt H, Barlogie B (2003) Angiogenesis in hematologic malignancies. Crit Rev Oncol Hematol 45:227-244

5. Folkman J, Hahnfeldt P, Hlatky L (2000) Cancer: looking outside the genome. Nat Rev Mol Cell Biol 1:76-79

6. Vaupel P (2004) Tumor microenvironmental physiology and its implications for radiation oncology. Semin Radiat Oncol 14:198-206

7. Moeller BJ, Richardson RA, Dewhirst MW (2007) Hypoxia and radiotherapy: opportunities for improved outcomes in cancer treatment. Cancer Metastasis Rev 26:241-248

8. Cardone RA, Casavola V, Reshkin SJ (2005) The role of disturbed $\mathrm{pH}$ dynamics and the $\mathrm{Na}+/ \mathrm{H}+$ exchanger in metastasis. Nat Rev Cancer 5:786-795

9. Kim JW, Gao P, Dang CV (2007) Effects of hypoxia on tumor metabolism. Cancer Metastasis Rev 26:291-298
10. Bilton R, Trottier E, Pouyssegur J, Brahimi-Horn MC (2006) ARDent about acetylation and deacetylation in hypoxia signalling. Trends Cell Biol 16:616-621

11. Brahimi-Horn MC, Pouyssegur J (2007) Oxygen, a source of life and stress. FEBS Lett 581:3582-3591

12. Pouyssegur J, Dayan F, Mazure NM (2006) Hypoxia signalling in cancer and approaches to enforce tumour regression. Nature 441:437-443

13. Coleman ML, Ratcliffe PJ (2007) Oxygen sensing and hypoxiainduced responses. Essays Biochem 43:1-16

14. Schofield CJ, Ratcliffe PJ (2005) Signalling hypoxia by HIF hydroxylases. Biochem Biophys Res Commun 338:617-626

15. Schofield CJ, Ratcliffe PJ (2004) Oxygen sensing by HIF hydroxylases. Nat Rev Mol Cell Biol 5:343-354

16. Semenza GL (2003) Targeting HIF-1 for cancer therapy. Nat Rev Cancer 3:721-732

17. Manalo DJ, Rowan A, Lavoie T, Natarajan L, Kelly BD, Ye SQ, Garcia JG, Semenza GL (2005) Transcriptional regulation of vascular endothelial cell responses to hypoxia by HIF-1. Blood 105:659-669

18. Semenza GL (2007) Oxygen-dependent regulation of mitochondrial respiration by hypoxia-inducible factor 1 . Biochem $\mathrm{J} 405$ : $1-9$

19. Ferrara N, Kerbel RS (2005) Angiogenesis as a therapeutic target. Nature 438:967-974

20. Dayan F, Roux D, Brahimi-Horn MC, Pouyssegur J, Mazure NM (2006) The oxygen sensor factor-inhibiting hypoxia-inducible factor-1 controls expression of distinct genes through the bifunctional transcriptional character of hypoxia-inducible factor1alpha. Cancer Res 66:3688-3698

21. Gordan JD, Thompson CB, Simon MC (2007) HIF and c-Myc: sibling rivals for control of cancer cell metabolism and proliferation. Cancer Cell 12:108-113

22. Brahimi-Horn MC, Pouyssegur J (2005) The hypoxia-inducible factor and tumor progression along the angiogenic pathway. Int Rev Cytol 242:157-213

23. Maiuri MC, Le Toumelin G, Criollo A, Rain JC, Gautier F, Juin P, Tasdemir E, Pierron G, Troulinaki K, Tavernarakis N, Hickman JA, Geneste O, Kroemer G (2007) Functional and physical interaction between Bcl-X(L) and a BH3-like domain in Beclin-1. EMBO J 26:2527-2539

24. Mazure NM, Bellot G, Garcia-Medina R, Gounon P, Roux D, Pouyssegur J (2007) Hypoxia-induced autophagy is mediated through the HIF-dependent induction of BNIP3 and BNIP3L. Bull Cancer 94:534

25. Maiuri MC, Zalckvar E, Kimchi A, Kroemer G (2007) Self-eating and self-killing: crosstalk between autophagy and apoptosis. Nat Rev Mol Cell Biol 8:741-752

26. Fantin VR, St-Pierre J, Leder P (2006) Attenuation of LDH-A expression uncovers a link between glycolysis, mitochondrial physiology, and tumor maintenance. Cancer Cell 9:425-434

27. Kim JW, Tchernyshyov I, Semenza GL, Dang CV (2006) HIF1-mediated expression of pyruvate dehydrogenase kinase: a metabolic switch required for cellular adaptation to hypoxia. Cell Metab 3:177-185

28. Papandreou I, Cairns RA, Fontana L, Lim AL, Denko NC (2006) HIF-1 mediates adaptation to hypoxia by actively downregulating mitochondrial oxygen consumption. Cell Metab 3:187-197

29. Fukuda R, Zhang H, Kim JW, Shimoda L, Dang CV, Semenza GL (2007) HIF-1 regulates cytochrome oxidase subunits to optimize efficiency of respiration in hypoxic cells. Cell 129:111-122

30. Kim JW, Gao P, Liu YC, Semenza GL, Dang CV (2007) HIF-1 and dysregulated c-Myc cooperatively induces VEGF and metabolic switches, HK2 and PDK1. Mol Cell Biol 27:7381-7393 
31. Swietach P, Vaughan-Jones RD, Harris AL (2007) Regulation of tumor $\mathrm{pH}$ and the role of carbonic anhydrase 9. Cancer Metastasis Rev 26:299-310

32. Counillon L, Pouyssegur J (2000) The expanding family of eucaryotic $\mathrm{Na}(+) / \mathrm{H}(+)$ exchangers. J Biol Chem 275:1-4

33. Sardet C, Franchi A, Pouyssegur J (1989) Molecular cloning, primary structure, and expression of the human growth factoractivatable $\mathrm{Na}+\mathrm{H}+$ antiporter. Cell 56:271-80

34. Shimoda LA, Fallon M, Pisarcik S, Wang J, Semenza GL (2006) HIF-1 regulates hypoxic induction of NHE1 expression and alkalinization of intracellular $\mathrm{pH}$ in pulmonary arterial myocytes. Am J Physiol Lung Cell Mol Physiol 291:L941-L949

35. Ullah MS, Davies AJ, Halestrap AP (2006) The plasma membrane lactate transporter MCT4, but not MCT1, is up-regulated by hypoxia through a HIF-1alpha dependent mechansm. J Biol Chem 281:9030-9037

36. Ivanov S, Liao SY, Ivanova A, Danilkovitch-Miagkova A, Tarasova N, Weirich G, Merrill MJ, Proescholdt MA, Oldfield EH, Lee J, Zavada J, Waheed A, Sly W, Lerman MI, Stanbridge EJ (2001) Expression of hypoxia-inducible cell-surface transmembrane carbonic anhydrases in human cancer. Am J Pathol 158:905-919

37. Becker HM, Hirnet D, Fecher-Trost C, Sultemeyer D, Deitmer JW (2005) Transport Activity of MCT1 Expressed in Xenopus Oocytes Is Increased by Interaction with Carbonic Anhydrase. J Biol Chem 280:39882-39889

38. Morgan PE, Pastorekova S, Stuart-Tilley AK, Alper SL, Casey JR (2007) Interactions of transmembrane carbonic anhydrase, CAIX, with bicarbonate transporters. Am J Physiol Cell Physiol 293: C738-748

39. Piermarini PM, Kim EY, Boron WF (2007) Evidence against a direct interaction between intracellular carbonic anhydrase II and pure C-terminal domains of SLC4 bicarbonate transporters. J Biol Chem 282:1409-1421

40. Chiche J, Laferrière J, Trottier E, Roux D, Mazure N, BrahimiHorn MC, Pouysségur J (2007) The hypoxia-induced tumor marker carbonic anhydrase IX plays a critical role in tumor microenvironmental $\mathrm{pH}$ homeostasis. Keystone Symposium Conference. Molecular Targets for Cancer. Abstract \# 134, Whistler, British Columbia, 18-23 March

41. Sullivan R, Graham CH (2007) Hypoxia-driven selection of the metastatic phenotype. Cancer Metastasis Rev 26:319-331

42. Yang J, Mani SA, Weinberg RA (2006) Exploring a new twist on tumor metastasis. Cancer Res 66:4549-4552

43. Gort EH, van Haaften G, Verlaan I, Groot AJ, Plasterk RH, Shvarts A, Suijkerbuijk KP, van Laar T, van der Wall E, Raman V, van Diest PJ, Tijsterman M, Vooijs M (2007) The TWIST1 oncogene is a direct target of hypoxia-inducible factor-2alpha. Oncogene (in press). DOI 10.1038/sj.onc.1210795

44. Walenta S, Mueller-Klieser WF (2004) Lactate: mirror and motor of tumor malignancy. Semin Radiat Oncol 14:267-274

45. Erler JT, Bennewith KL, Nicolau M, Dornhofer N, Kong C, Le QT, Chi JT, Jeffrey SS, Giaccia AJ (2006) Lysyl oxidase is essential for hypoxia-induced metastasis. Nature 440:1222-1226

46. Petrella BL, Lohi J, Brinckerhoff CE (2005) Identification of membrane type-1 matrix metalloproteinase as a target of hypoxiainducible factor- 2 alpha in von Hippel-Lindau renal cell carcinoma. Oncogene 24:1043-1052

47. Chan DA, Giaccia AJ (2007) Hypoxia, gene expression, and metastasis. Cancer Metastasis Rev 26:333-339
48. Larson SM (2004) Positron emission tomography-based molecular imaging in human cancer: exploring the link between hypoxia and accelerated glucose metabolism. Clin Cancer Res 10:2203-2204

49. Cherk MH, Foo SS, Poon AM, Knight SR, Murone C, Papenfuss AT, Sachinidis JI, Saunder TH, O, Keefe GJ, Scott AM (2006) Lack of correlation of hypoxic cell fraction and angiogenesis with glucose metabolic rate in non-small cell lung cancer assessed by 18 F-Fluoromisonidazole and 18F-FDG PET. J Nucl Med 47:1921-1926

50. Rajendran JG, Mankoff DA, O, Sullivan F, Peterson LM, Schwartz DL, Conrad EU, Spence AM, Muzi M, Farwell DG, Krohn KA (2004) Hypoxia and glucose metabolism in malignant tumors: evaluation by [18F]fluoromisonidazole and [18F]fluorodeoxyglucose positron emission tomography imaging. Clin Cancer Res 10:2245-2252

51. Kaelin WG Jr (2007) The von Hippel-Lindau tumor suppressor protein and clear cell renal carcinoma. Clin Cancer Res 13:680s-684s

52. Trastour C, Benizri E, Ettore F, Ramaioli A, Chamorey E, Pouyssegur J, Berra E (2007) HIF-1alpha and CA IX staining in invasive breast carcinomas: prognosis and treatment outcome. Int J Cancer 120:1451-1458

53. Van den Eynden GG, Van der Auwera I, Van Laere SJ, Colpaert CG, Turley H, Harris AL, van Dam P, Dirix LY, Vermeulen PB, Van Marck EA (2005) Angiogenesis and hypoxia in lymph node metastases is predicted by the angiogenesis and hypoxia in the primary tumour in patients with breast cancer. $\mathrm{Br} \mathrm{J}$ Cancer 93:1128-1136

54. Hussain SA, Ganesan R, Reynolds G, Gross L, Stevens A, Pastorek J, Murray PG, Perunovic B, Anwar MS, Billingham L, James ND, Spooner D, Poole CJ, Rea DW, Palmer DH (2007) Hypoxia-regulated carbonic anhydrase IX expression is associated with poor survival in patients with invasive breast cancer. Br J Cancer 96:104-109

55. Tan EY, Campo L, Han C, Turley H, Pezzella F, Gatter KC, Harris AL, Fox SB (2007) BNIP3 as a progression marker in primary human breast cancer; opposing functions in in situ versus invasive cancer. Clin Cancer Res 13:467-474

56. Giatromanolaki A, Koukourakis MI, Sowter HM, Sivridis E, Gibson S, Gatter KC, Harris AL (2004) BNIP3 expression is linked with hypoxia-regulated protein expression and with poor prognosis in non-small cell lung cancer. Clin Cancer Res 10:5566-5571

57. Verheul HM, Pinedo HM (2007) Possible molecular mechanisms involved in the toxicity of angiogenesis inhibition. Nat Rev Cancer 7:475-485

58. Melillo G (2007) Targeting hypoxia cell signaling for cancer therapy. Cancer Metastasis Rev 26:341-352

59. Pelicano H, Martin DS, Xu RH, Huang P (2006) Glycolysis inhibition for anticancer treatment. Oncogene 25:4633-4646

60. Thiry A, Dogne JM, Masereel B, Supuran CT (2006) Targeting tumor-associated carbonic anhydrase IX in cancer therapy. Trends Pharmacol Sci 27:566-573

61. Izumi $\mathrm{H}$, Torigoe $\mathrm{T}$, Ishiguchi $\mathrm{H}$, Uramoto $\mathrm{H}$, Yoshida $\mathrm{Y}$, Tanabe M, Ise T, Murakami T, Yoshida T, Nomoto M, Kohno K (2003) Cellular $\mathrm{pH}$ regulators: potentially promising molecular targets for cancer chemotherapy. Cancer Treat Rev 29:541-459

62. Gerweck LE, Vijayappa S, Kozin S (2006) Tumor pH controls the in vivo efficacy of weak acid and base chemotherapeutics. Mol Cancer Ther 5:1275-1279 